\title{
Currency, Spelling, and Translation
}

The currency unit in Brazil throughout the period of this book was the milréis. One milréis was written as $1 \$ 000$, and it was the equivalent of one thousand reis (plural of real). One thousand milréis was the equivalent of one conto de réis, or 1:00o\$0oo. Sources of historical exchange rate and costof-living data are cited in the endnotes. In addition, the Portuguese language had not yet been orthographically standardized in the early twentieth century. For proper names, I use the most common spelling that appeared in the documentation. I spell all proper names of places and other Portuguese words according to present-day conventions. All translations are mine unless otherwise noted. 


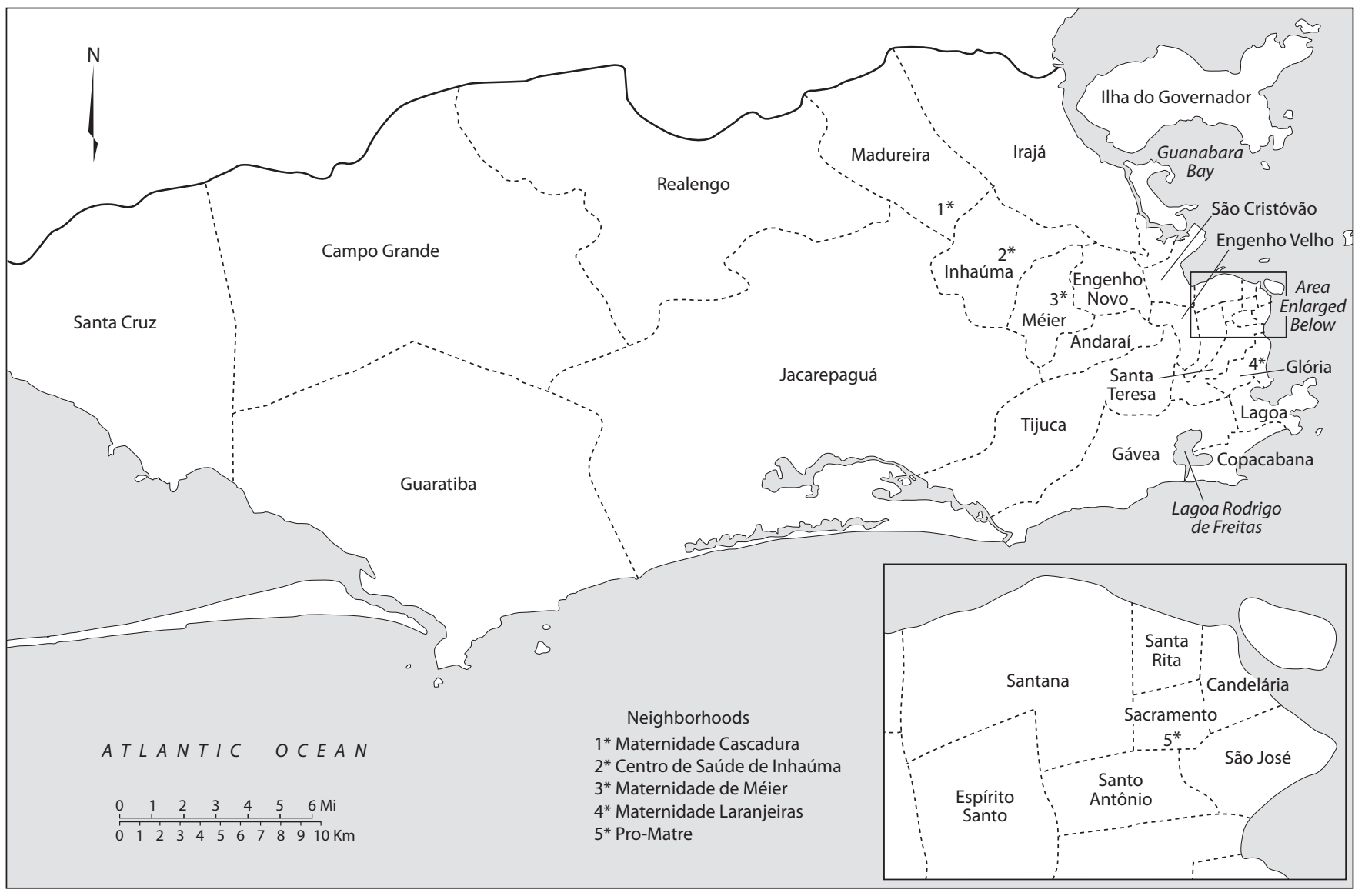

Districts and neighborhoods of Rio de Janeiro, early twentieth century 